\title{
Hasan Dikyuva, Bahtiyar Makaroğlu, Engin Arık "Türk İşaret Dili Dilbilgisi Kitabı" Aile ve Sosyal Politikalar Bakanlığı, Ankara 2015, 352 s. ISBN: 978-605-4628-84-1
}

\section{Abdullah TOPRAKSOY* (1)}

"Sorumlu yazar/Corresponding author: Abdullah Topraksoy (Arş. Gör.), İstanbul Üniversitesi, Edebiyat Fakültesi, Dilbilimi Bölümü, İstanbul, Türkiye E-posta: abdullah.topraksoy@istanbul.edu.tr ORCID: 0000-0003-3240-3915

Başvuru/Submitted: 18.06 .2019 Kabul/Accepted: 14.08.2019

Atıf/Citation: Topraksoy, A. (2020). Türk Işaret Dili Dilbilgisi Kitabı [Hasan Dikyuva, Bahtiyar Makaroğlu ve Engin Arık tarafından yayına hazırlanan Türk Iş̧aret Dili Dilbilgisi Kitabı başlıklı kitabın değerlendirmesi]. Dilbilim Dergisi Journal of Linguistics, 34, 73-75. https://doi.org/10.26650/jol.2020.005

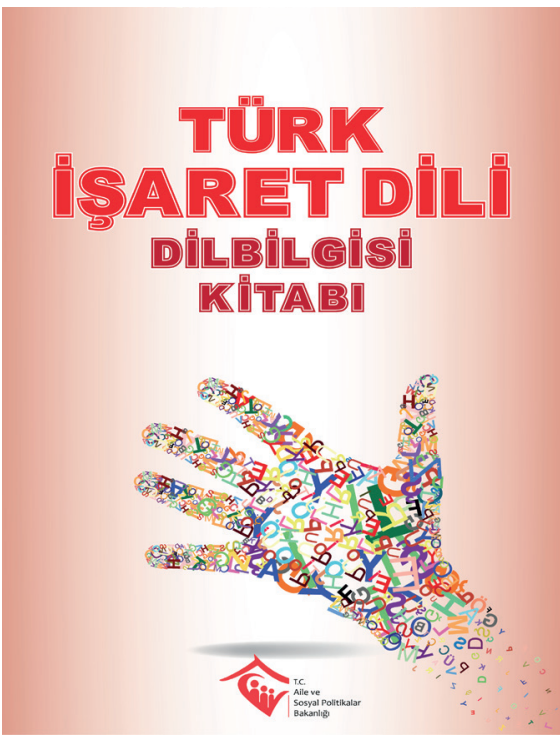

Dile dair yapılan çalışma ve araştırmalar, uzun zaman önce konuşma dilinin söyleniş özelliklerini betimleme ve güzel konuşma sanatını tanımlama gibi pratik amaçlar yoluyla Eski Yunan ve Roma'ya kadar uzansa da, modern bir bilim olarak dilbilimsel çalışmalar 20. yüzyılın ilk yarısında F. de Saussure ile başlamıştır. İşaret diline ilişkin dilbilimsel çalışmalar ise W. Stokoe ile 1960'lı yıllarda ortaya çıkmasına rağmen, ülkemizdeki çalışmaların ancak 2000'li yıllarda boy göstermeye başladığını söyleyebiliriz. Bu bağlamda, hem işaret dili alanyazınına hem de toplumumuzun işaret dili hakkında daha kapsamlı olarak bilgilenmesine önemli katkı sağlayan “Türk İşaret Dili Dilbilgisi Kitabı”, Aile ve Sosyal Politikalar Bakanlığı’nın desteğiyle 
ve başlıkta isimleri anılan işaret dili akademisyenlerinin katkılarıyla ortaya çıkan, 26 ilden anadili Türk İşaret Dili (TID) olan katılımcılardan elde edilen bilgilerin bilgisayarlı dilbilim ve derlemdilbilimi yöntemleriyle işlenmesi sonucu elde edilmiş geniş boyutlu bir derlem (yaklaşık 800.000 sözcükten oluşan 6.240 dakikalık kayıt) çalışmasının ürünüdür.

Elimizdeki bu kitap, işaret dillerine ilişkin genel bilgiler ile Türk İşaret Dili’nin tanıtımını içeren ve bu kitabının ortaya çıkışını sağlayan projeye dair bilgileri bulacağınız bir giriş; işaret dili ve toplum ilişkisini irdeleyen bir Toplumdilbilimsel bölüm; işaret dilini ses, biçim, sözdizimi ve anlam yapıları bakımından inceleyen yapısal bölümler dizisi ve sonuç olmak üzere 4 anahat üzerine biçimlendirilmiş ve toplamda 7 bölümden oluşmuştur.

Kitabın bölümlerini detaylandıracak olursak, ilk bölümde işaret dilleri hakkında birtakım genel bilgiler verilmekte ve işaret dilleriyle konuşma dilleri dil modalitesi bakımından karşılaştırılmaktadır. Bölümün devamında ise TİD üzerine yapılan yakın zamandaki çalışmalara dair bilgiler verilmiş ve bu dilin kullanımında coğrafi bakımdan farklılıkların olup olmadığı tartışılmıştır. Bölüm, kitabın ortaya çıkışını sağlayan proje çalışması hakkında yöntemsel bilgiler, verilerin toplanmasına ilişkin sürecin anlatıldığı saha çalışması bilgileri, katılımcılar hakkındaki demografik bilgiler ve verilerin kodlanmasına ilişkin bilgilerin sunumuyla sonlandırılmıştır.

İşaret dili ve işaret dilinin toplumdaki yeri bağlamında şekillenen ikinci bölümde, 'işitme engellilik', sağırlık ve Sağır toplum kavramları üzerinde durulmuş; TİD hakkında tarihsel bilgilere yer verilmiş; ülkemizde bulunan Sağır toplum tanıtılmış ve dil etkileşimi çerçevesinde iki dillilik-çok dillilik kavramlarına değinilmiştir. Son olarak, TİD el abecesi görsellerle anlatılmış ve her ne kadar TİD' in dilbilgisi kuralları olsa da kimi zaman sağır ile konuşan ya da TİD'i sonradan edinen sağır birisi arasında Türkçe'nin dilbilgisi kurallarına benzeyen "İşaretlendirilmiş Türkçe” kanalıyla iletişim kurulduğu vurgulanmıştır.

'Sesbilgisi' ve ‘sesbilim' e karş1lık olarak ‘işaretbirimbilgisi' ve 'işaretbirimbilim' hakkında bilgilerin yer aldığ1 üçüncü bölümde, işaret oluşumunun (signing) dayandığ1 etmenler el ile yapılan ve el-dışı yapılar olarak iki grupta incelenmiş; bu yapıların eşzamanlı olarak kullanılmasının, işaret dillerini konuşma dillerinden ayıran önemli bir özellik olduğuna değinilmiştir. Ardından, işaret dilindeki ses (işaret) yapısı açıklanmış; dile ilişkin konum benzeşmesi (location assimilation), hareket düşmesi (movement deletion) ve el düşmesi (handshape deletion) gibi ses olayları, el abecesi örnekleriyle anlatılarak bölüm sonlandırılmıştır.

İşaret dilleri ve konuşma dillerindeki biçimbirimsel yapıların karşılaştırıldığı ve işaret dilindeki biçimbirimlerin sözcüksel-birleşimsel özellikleri aktarılan dördüncü bölümde; türetimsel-çekimsel yineleme, işaret birleşimi gibi kavramlar anlambilimsel ve sözdizimsel açıdan alt gruplarda anlatılmıştır. Bunlara ek olarak, ad ve eylem biçimlenişi ayrımı yapılmış ve bu ayrım adlar için konum, sayı, ebat ve şekil göstericisi, sınıflandırıcılar ve pekiştirme; eylemler için ise uyum, tarz, zaman-görünüş-kiplik ve işteşlik alt konularında detaylandırılarak aktarılmıştır. Bölüm sonunda, TİD’deki adıllar ve türlerine yer verilmiş; örnek tümceler üzerinde adılların gösterimi yapılmıştır. 
Sözdizim bağlamında tümce içinde sözcük dizilişi, ad öbekleri, olumsuzlama ve tümce yapılarına değinilen beşinci bölümde; geçişli-geçişsiz eylemlerde işaretlerin dizimi, tümce türleri (olumlu-olumsuz, basit-sıralı yapılı, soru ve yan tümce) ve olumsuz yapma gibi konular açıklanmış ve örneklerle pekiştirilmiştir.

Anlambilimsel olarak zengin bir içeriğe yer verilen altıncı bölümde; anlam ve gönderim, gösterimsellik, anlam türleri, metafor, sözce-tümce anlamı, söylem belirleyiciler ve deyimler alt başlıkları bulunmaktadır. Ayrıca, anlam türleri eş anlam, zıt anlam, çok anlam ve eş seslilik bağlamlarında ele alınmış; diğer bölümlerde olduğu gibi, işaret dilinden örnekler verilerek konu daha açık hale getirilmiştir. Bölüm, söylem belirleyiciler ve deyimlerin açıklanmasının ardından TİD'de kullanılan yapılar ve bu yapıların yer aldığı örnekler verilerek sonlandırılmıştır.

Kitabın kapanış bölümünde, kitabın ortaya çıkmasına dayanak olan yasal bilgiler (5378 sayılı Engelliler Hakkında Kanun'un 15' inci maddesi) verilmiş; kitap bölümlerinde anlatılan dilsel özelliklerin ve yapıların bu dilde de var olmasından dolayı TİD’ in doğal bir dil olduğu, kendine özgü dilbilgisi yapısı olduğu, TİD abecesinin Türkçe’nin yazılı dilinden etkilendiği fakat TID'e diğer işaret dillerinden bir etkinin olmadığı gibi noktalar vurgulanmıştır. Bunların yanı sıra, Anadolu' da işaret dilinin kullanımına ve tarihsel gelişimine kısaca değinilmiş; dildeki ses, biçim, tümce ve anlam yapıları bağlamında TİD’i incelemenin, dildeki zenginliği gösterdiği ifade edilmiştir. Son olarak, bu kitabın bizlere ulaşmasını sağlayan çalışmadaki kısıtlamalara yer verilmiş; bu eksikliklerin yeni çalışmalar yapılarak giderilmesinin ve bu yeni çalışmalarda elde edilen bilgilerin, kitabın yeni basımlarına eklenerek alandaki bilginin genişletilmesinin yararlı olacağına vurgu yapılmıştır.

“Türk İşaret Dili Dilbilgisi Kitabı”, işaret dilinin dilbilgisel yapısının bilimsel çerçevede anlatıldığı bir çalışma olarak alanda önemli bir yere sahiptir. Kitapta yer verilen dilsel yapıları barındırdığı kanıtından yola çıkarak TID' in görsel-uzamsal modaliteye sahip doğal bir olduğu gerçeği vurgulanmış; sesbilim, biçimbilim, anlambilim ve sözdizim gibi temel dilbilim alanlarındaki görünümü kapsamında Türkçe ile hangi açılardan benzerlik-farklılık gösterdiği betimlenmiş ve örneklerle zenginleştirilmiştir. Bunların yanı sıra, işaret diline dair genel bilgilere yer verilmiş ve işaret dili çalışmalarının tarihsel gelişimine değinilmiştir. TİD üzerine yazılan ilk dilbilgisi kitabı olması nedeniyle bu kitap, işaret dili alanına dilbilim bağlamında bilgisel ve betimsel olarak ciddi katkı sağlayan ve sağlamaya devam edecek olan, bunun yanında, toplumda işaret diline dair farkındalığın daha çok gelişmesine aracı olan değerli bir çalışma ürünüdür. 
